\title{
The Correlation between Study Habits and the Academic Achievement of High School Pupils
}

\author{
Asha Sasi ${ }^{1, *}$, Anju A. $\mathbf{R}^{2}$ \\ ${ }^{1}$ Mother Teresa College of Nursing, Maharashtra University of Health Sciences, India \\ ${ }^{2}$ Josco College of Nursing, Kerala University of Health Sciences, India
}

Received August 25, 2020; Revised November 13, 2020; Accepted November 29, 2020

\begin{abstract}
Cite This Paper in the following Citation Styles
(a): [1] Asha Sasi, Anju A R, "The Correlation between Study Habits and the Academic Achievement of High School Pupils," Universal Journal of Educational Research, Vol. 8, No. 12A, pp. 7359 - 7366, 2020. DOI: 10.13189/ujer.2020.082520.
\end{abstract}

(b): Asha Sasi, Anju A R (2020). The Correlation between Study Habits and the Academic Achievement of High School Pupils. Universal Journal of Educational Research, 8(12A), 7359 - 7366. DOI: 10.13189/ujer.2020.082520.

Copyright@2020 by authors, all rights reserved. Authors agree that this article remains permanently open access under the terms of the Creative Commons Attribution License 4.0 International License

\begin{abstract}
A descriptive survey was conducted to assess the correlation between study habits and academic achievements among high school pupils, in a nominated school at Alappuzha District, Kerala. Disproportionate stratified random selection was used to pick out 180 high school pupils. Information was collected by using the socio demographic questionnaire, Modified M. Mukhopadhaya's and D. N. Sansanwal's study habits inventory and the review of previous year progress reports. The data were tabulated and examined by means of descriptive and inferential measurements. The findings shown that the total mean score in study habits was 78.81 with SD 20.26 and the total mean score of academic achievements was 65.58 with SD 14.13. The calculated Karl Pearson correlation coefficient ' $r$ ' value $(0.808)$ was greater than the table value (0.191) and the degree of freedom 178 at $\mathrm{p}<0.01$ level of significance, indicating that there was a substantial positive correlation between Study Habits \& the Academic Achievements of high school pupils. Hence, the study judged that a rise in study habits score will also raise the academic achievement score among high school pupils.
\end{abstract}

Keywords Academic Achievement, High School Pupils, Study Habits

\section{Introduction}

Habits help the pupils to do things with less thought and struggle. It is important in shaping the characters of individuals. In the process of edification, study habits like thinking, reasoning, attention, punctuality, etc., enable the pupils to make proper alterations for better achievements [1].

Good study habits are the top secret to academic success in schools [2]. The development of good study habits is an art and it is the potential of individual student. Some pupils like to read alone, while some want to read in a group and some pupils read silently. There is no restricting yardstick to measure the type of study habits. It may be inherited or acquired. The student can formulate own study habits by himself or herself. Pupils should be made aware of the importance of it and proper training should be given right from childhood onwards [3].

Academic success is the sum of small efforts done by the pupils. The achievement of good study habits is the road to the goals of an individual. A simple, small modification in study routines makes a big variance in aim set and shapes one's life. [4].

In pupils, academic success plays an important role in teaching as well as in the learning course. It has been one of the best significant aims of the entire edifying progression. The valuable outcome of any edifying set up is the success of pupils in their academics. Based on the level of accomplishment, persons are categorized as good, average and poor.

Academic success is one of the objectives of edification. The educational competence of the student is judged by his accomplishments in the school [5]. The aim of all academic and non-academic happenings in the school is basically to boost the academic achievements of the pupils. 
It is affected by several personal, institutional, social and economic aspects [6].

In many research studies, Educational Psychologists show a strong correlation between Study Habits \& Academic Achievements. Taylor (1964) depicted that the value the student gives upon his own worth, affects his or her academic achievements. Academic achievements of a pupil refer to the information accomplished and abilities developed in the school subjects. So academic achievements mean the accomplishment of pupils in the academic subjects. [7]

A survey study was conducted at Mysore city (2016) to assess Study Habits \& Academic Achievement of 625 secondary and senior secondary school pupils studying in $9^{\text {th }}, 10^{\text {th }}, 11^{\text {th }}$ and $12^{\text {th }}$ were selected randomly and data were collected through study habits and attitudes scale established by C.P. Mathur and their previous annual term examination reports, and the results indicated that $71 \%$ had average study habits, $27 \%$ had poor and $1.9 \%$ had good study habits. It showed that those pupils who were good in study habits were also good in academic achievements, $(M=82.25)$ and those who were poor in study habits were also slow in their academic achievements ( $\mathrm{M}=72.83)$ [8].

\subsection{Need and Significance of the Problem}

Pupils are the leaders of tomorrow who need to be armed with a strong value system and enabling habits which can aid them to lead a well and more rewarding life. In the present academic circumstances, they need to be equipped with good study habits for succeeding in academic life. Study habits or study skills are methods applied to education. They are generally needed to success in schools, and are useful for learning throughout one's life [9].

A student's growth or lack of success in the classroom depends upon numerous factors like attention on the subject, inspiration to learn, study amenities, study habits and so on. Some pupils attribute their academic letdown to such factors as low aptitude, inaccessibility of resources, and bad luck. We can dare to say that the most significant factor playing a role in academic triumph is the pupils' little acquaintance with learning and study skills [10]

Study habits differ from student to student. Some study habits are more beneficial than others from the point of view of academic achievement. Satisfactory health, proper sleep, proper exercise, and good nutritious diet are very much vital for the accomplishment of upright study outcomes. Study circumstances that are un-favorable include insufficient light, dangerous temperatures, dampness, deprived body posture, abnormal physical circumstances, and emotional troubles [11]. Pupils have different approaches to choose the learning environment for their studying [12].

The National Commission on Excellence in Education endorses that study habits, skills and attitude be familiarized to a student very early in the childhood period and remain lifelong of a student's educational career. $75 \%$ of pupils who are academic underperformers have poor study habits and examination techniques [13].

Academic achievement is the outcome of education. It is mainly measured by formative or summative assessment techniques. School procurement might be influenced by different aspects resembling study habits, memory power and the way of behavior of learners towards school, financial status and a different kind of their personality. In our community, academic achievement is observed as an important concept to justify the individual's whole capacities and potentialities [9].

\subsection{Statement of the Problem}

A study to evaluate the correlation between Study Habits and the Academic Achievements of high school pupils in a selected school at Alappuzha District.

\subsection{Purpose of the Study}

The purpose of the study was to evaluate the correlation between Study Habits and the Academic Achievements of high school pupils.

\subsection{Objectives}

1. To assess the study habits of high school pupils.

2. To assess the level of academic achievements of high school pupils.

3. To find out the correlation between study habits and the academic achievements of high school pupils.

\section{Methodology}

\subsection{Study Design}

Descriptive correlation survey design which is one of the quantitative research methods was used in the study.

\subsection{Sample and Sampling Technique}

The study was carried out with 180 high school pupils in the age group of 13-16 years who were studying in $8^{\text {th }}$, $9^{\text {th }}$ and $10^{\text {th }}$ standards and the sampling technique was probability disproportionate stratified random sampling. 
Table 1. Personal information of the participants

\begin{tabular}{|c|c|c|c|}
\hline Personal Data & & n & $\%$ \\
\hline \multirow{3}{*}{ Age in years } & $13-14$ & 60 & 33.3 \\
\hline & $14-15$ & 60 & 33.3 \\
\hline & $15-16$ & 60 & 33.3 \\
\hline \multirow{2}{*}{ Gender } & Male & 90 & 50 \\
\hline & Female & 90 & 50 \\
\hline \multirow{3}{*}{ Religion } & Hindu & 95 & 52.8 \\
\hline & Christian & 82 & 45.5 \\
\hline & Muslim & 3 & 1.7 \\
\hline \multirow{3}{*}{ Class of study } & $8^{\text {th }}$ standard & 60 & 33.3 \\
\hline & $9^{\text {th }}$ standard & 60 & 33.3 \\
\hline & $10^{\text {th }}$ standard & 60 & 33.3 \\
\hline \multirow{2}{*}{ Area of residence } & Panchayath & 170 & 94.5 \\
\hline & Municipality & 10 & 5.5 \\
\hline \multirow{2}{*}{ Type of family } & Nuclear family & 167 & 92.7 \\
\hline & Joint family & 13 & 7.3 \\
\hline \multirow{4}{*}{ Family income per month } & $\leq$ Rs.10,000/- & 61 & 33.8 \\
\hline & Rs. 10,001 - Rs. $20,000 /-$ & 58 & 32.3 \\
\hline & Rs. 20,001 - Rs. 30,000/- & 30 & 16.6 \\
\hline & $\geq$ Rs. $30,001 /-$ & 31 & 17.3 \\
\hline \multirow{5}{*}{ Education of father } & Up to high school & 28 & 15.6 \\
\hline & Higher secondary & 49 & 27.2 \\
\hline & Diploma & 51 & 28.4 \\
\hline & Graduation & 35 & 19.4 \\
\hline & Post-graduation and above & 17 & 9.4 \\
\hline \multirow{5}{*}{ Education of mother } & Up to high school & 20 & 11.1 \\
\hline & Higher secondary & 46 & 25.5 \\
\hline & Diploma & 45 & 25 \\
\hline & Graduation & 56 & 31.2 \\
\hline & Post-graduation and above & 13 & 7.2 \\
\hline \multirow{5}{*}{ Occupation of father } & Government employee & 23 & 12.8 \\
\hline & Private employee & 102 & 56.7 \\
\hline & Self-employed & 44 & 24.5 \\
\hline & Daily Wager & 8 & 4.4 \\
\hline & Unemployed & 3 & 1.6 \\
\hline \multirow{5}{*}{ Occupation of mother } & Government employee & 22 & 12.3 \\
\hline & Private employee & 29 & 16.2 \\
\hline & Self-employed & 6 & 3.3 \\
\hline & Daily Wager & 01 & 0.5 \\
\hline & Homemaker & 122 & 67.7 \\
\hline \multirow{4}{*}{ Number of siblings } & Nil & 29 & 16.2 \\
\hline & One & 133 & 73.8 \\
\hline & Two & 18 & 10 \\
\hline & Three and above & 0 & 0 \\
\hline \multirow{3}{*}{ Birth order } & First & 109 & 60.6 \\
\hline & Second & 64 & 35.6 \\
\hline & Third and above & 7 & 3.8 \\
\hline \multirow{4}{*}{ Number of close friends } & Nil & 2 & 1.2 \\
\hline & $1-2$ & 19 & 10.5 \\
\hline & $3-5$ & 40 & 22.2 \\
\hline & More than 5 & 119 & 66.1 \\
\hline
\end{tabular}


Table 1 Continued

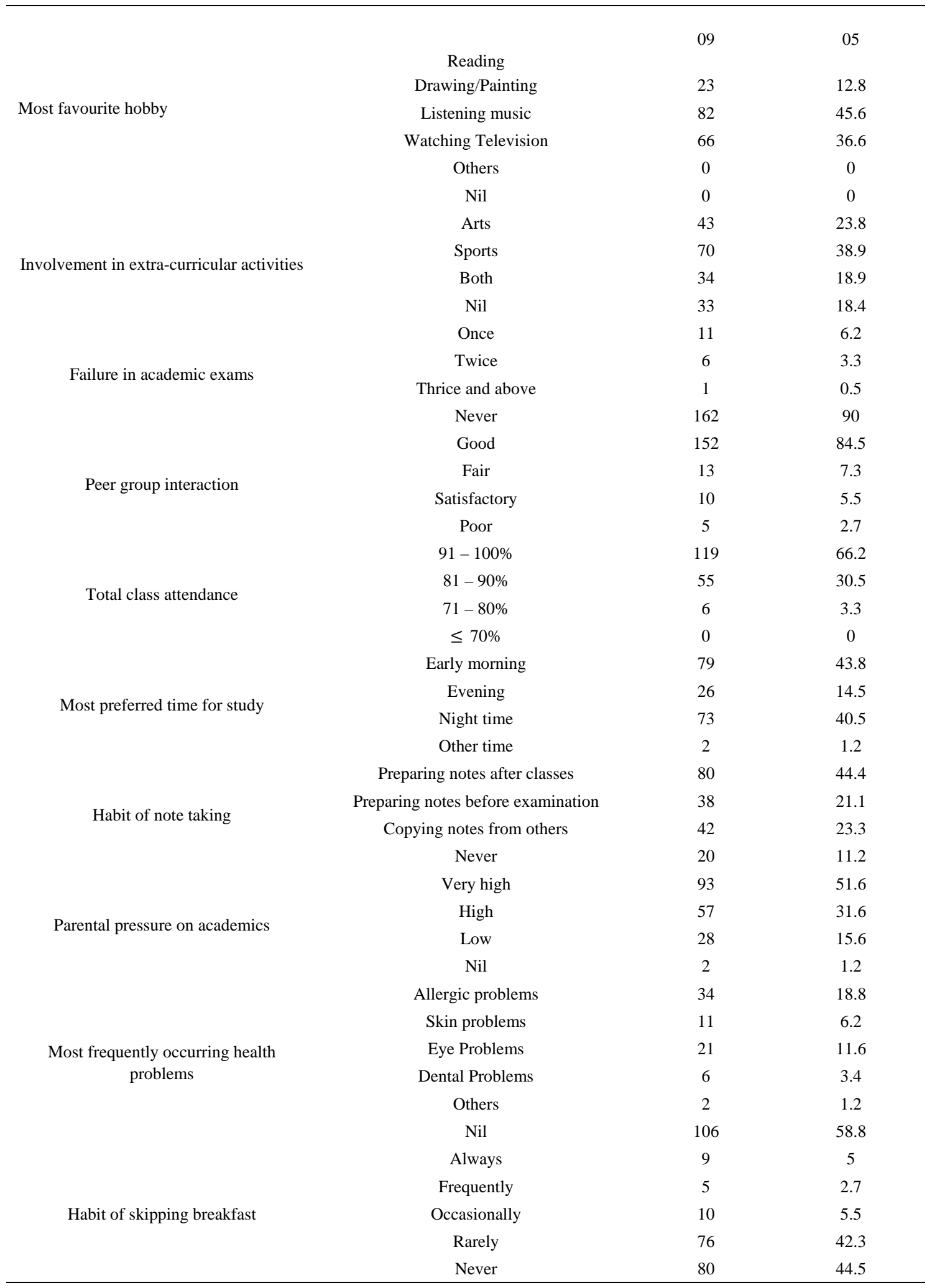




\subsection{Tool}

The tool used in this study consists of personal data form which was established by the researcher in order to assess the socio-demographical variables of the study participants. To assess the study habits of high school pupils, researcher used Modified M. Mukhopadhaya's and D. N. Sansanwal's study habits inventory (SHI). It is a 5 -point rating scale. The inventory contains 35 statements and each statement is from 5 different areas like comprehension, concentration, task orientation, interaction and recording and for every statement it has 5 options such as always, frequently, sometimes, rarely and never. In SHI it consists of positive statements 1, 2, 3, 4, 5, $6,7,9,10,17,19,21,22,23,28,31,32,35$ and negative statements $8,11,12,13,14,15,16,18,20,24,25,26,27$, $29,30,33,34$. The scoring of positive statements $4,3,2,1$, 0 and the scoring of negative statements $0,1,2,3,4$. The total statements were 35 . Therefore $140(4 \times 35)$ is the maximum possible score. The reliability of the study habits inventory was established by Cronbach's alpha and the score was 0.728 . In order to infer the content validity of this tool, the tool along with the problem statement, objectives, hypotheses and operational definitions was given to 10 experts.

For assessing the academic achievement of high school pupils, researcher used the technique of retrospective record reviewing of previous academic year progress report of high school pupils studying in $8^{\text {th }}, 9^{\text {th }}$, and $10^{\text {th }}$ standard and that is evaluated by cumulative grade point average and their assessment grades were converted into standard numerical scores.

\subsection{Data Collection Process}

For conducting the main study, prior approval was acquired from the Principal of selected school and the data were collected from $8^{\text {th }}, 9^{\text {th }}$, and $10^{\text {th }}$ standard, pupils were selected based on age, class of study and gender. Each standard consisted of A, B and C divisions. Each division had strength of 25 to 35 pupils. Then the researcher chose different sampling fractions and by simple random sampling technique using lottery non replacement method,
10 males and 10 females were selected from each division. Hence in total 60 samples from $8^{\text {th }}, 9^{\text {th }}$, and $10^{\text {th }}$ standard.

On $1^{\text {st }}$ day informed consent was given to the parents of 20 pupils by sending the consent form along with the pupils after elucidating the purpose of the study and on the next day the data were collected using socio demographic proforma, modified M. Mukhopadhaya's and D. N. Sansanwal's study habits inventory, by the review of the progress reports, and distribution of the information booklets among 20 pupils. The above same step was repeated for the remaining selected samples. The time taken by each candidate to fill the questionnaire was 20-25 minutes.

\subsection{Data Analysis}

\subsubsection{Descriptive statistics:}

Frequency and percentage distribution was used to evaluate the socio demographic variables. Mean, percentage and standard deviation were used to analyze the scores on Study Habits \& Academic Achievement.

\subsubsection{Inferential statistics:}

Karl pearson co-efficient of correlation was used to find out the correlation between Study Habits \& Academic Achievement of high school pupils. Chi-square test was used to find out the association between research variables and the selected socio demographic variables.

\section{Results}

The major findings of the study are presented below. Figure 1illustrates that (61.7\%) of the subjects had satisfactory study habits. Figure 2 indicates that (45.6\%) of the subjects had good academic achievement. Figure 3 reveals that direction of scattered plots falling from the lower left corner to the upper right corner indicates that there is a positive correlation between the study habits and the academic achievements among high school students. That means the score of academic achievement (vertical variable) is directly proportional to the score of study habits (horizontal variable). 


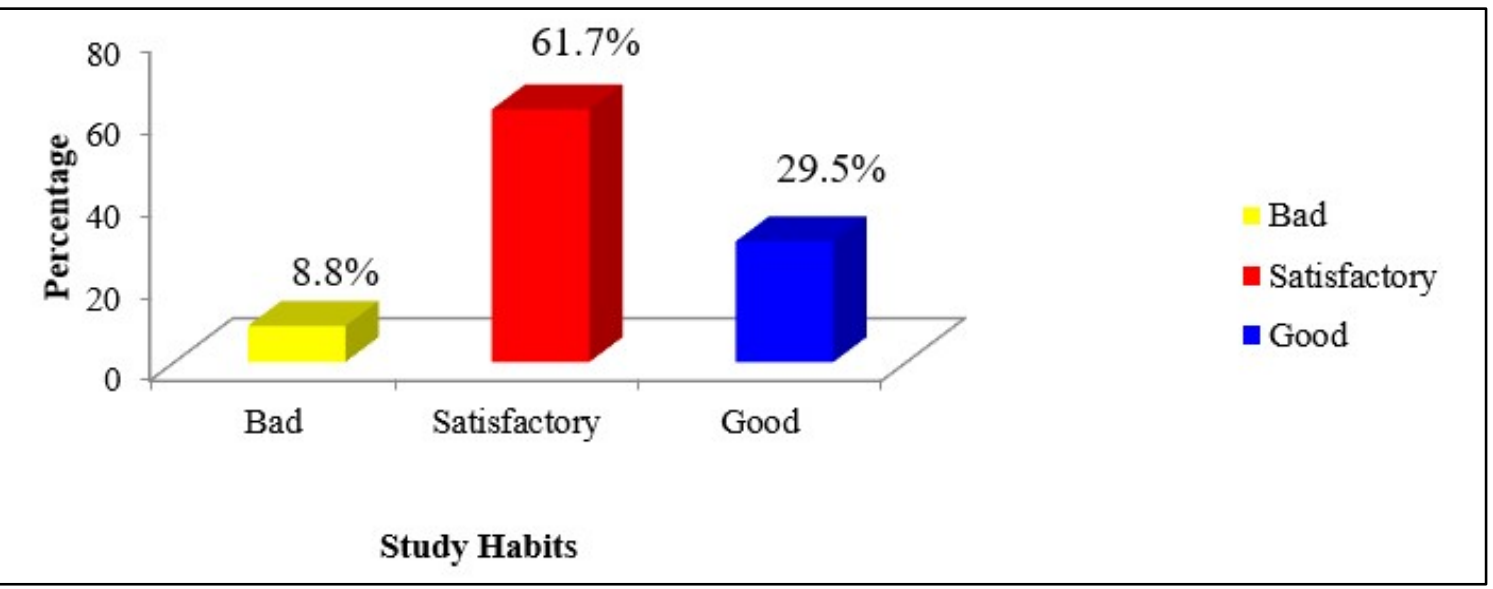

Figure 1. Bar diagram showing percentage distribution of subjects based on study habits. $(n=180)$

Table 2. Mean, Standard Deviation, Mean Percentage, minimum and maximum scores of areas of study habits among high school pupils. ( $\mathrm{n}=180$ )

\begin{tabular}{|c|c|c|c|c|c|}
\hline Areas of study habits & Mean & SD & Minimum & Maximum & Mean\% \\
\hline Comprehension & 29.3 & 8.48 & 9 & 47 & $61.04 \%$ \\
\hline Concentration & 19.85 & 7.25 & 2 & 34 & $49.62 \%$ \\
\hline Task orientation & 16.97 & 5.15 & 4 & 30 & $53.03 \%$ \\
\hline Interaction & 7.35 & 2.81 & 0 & 12 & $61.25 \%$ \\
\hline Recording & 5.34 & 1.83 & 0 & 8 & $66.75 \%$ \\
\hline Total & 78.81 & 20.26 & 0 & 47 & $58.33 \%$ \\
\hline
\end{tabular}

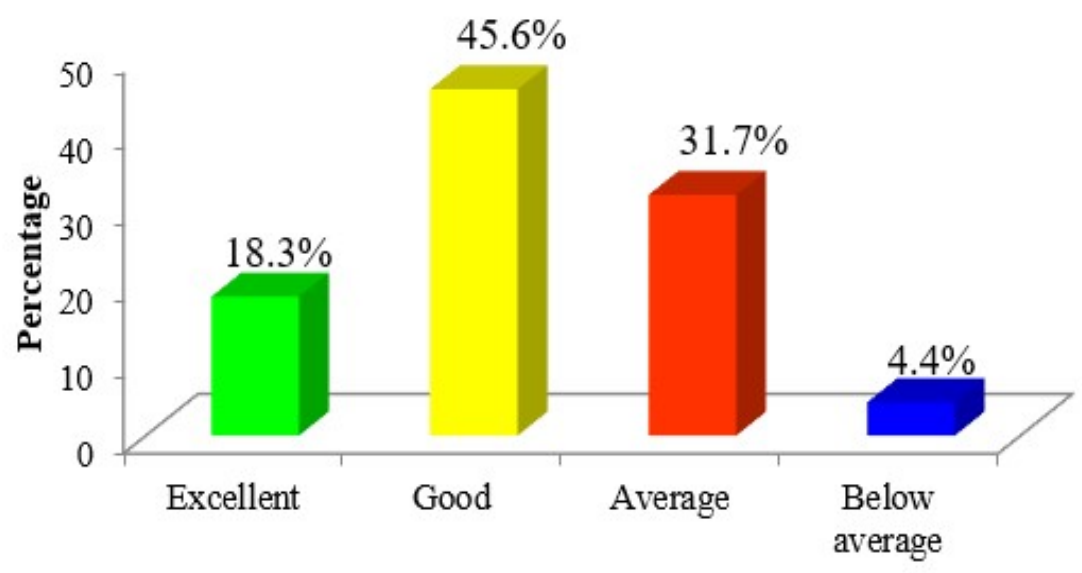

Excellent

Good

- Average

- Below average

\section{Academic Achievement}

Figure 2. Bar diagram showing percentage distribution of subjects based on academic achievements. $(\mathrm{n}=180)$

Table 3. Correlation between the study habits and the academic achievements of high school pupils. ( $\mathrm{n}=180)$

\begin{tabular}{|c|c|c|c|c|}
\hline Variables & Mean & SD & DF & Pearson correlation \\
\cline { 1 - 3 } Study habits & 78.81 & 20.26 & \multirow{2}{*}{178} & 0.808 \\
\hline Academic achievement & 65.58 & 14.13 & & \\
\hline
\end{tabular}

** Significant at 0.01 level 


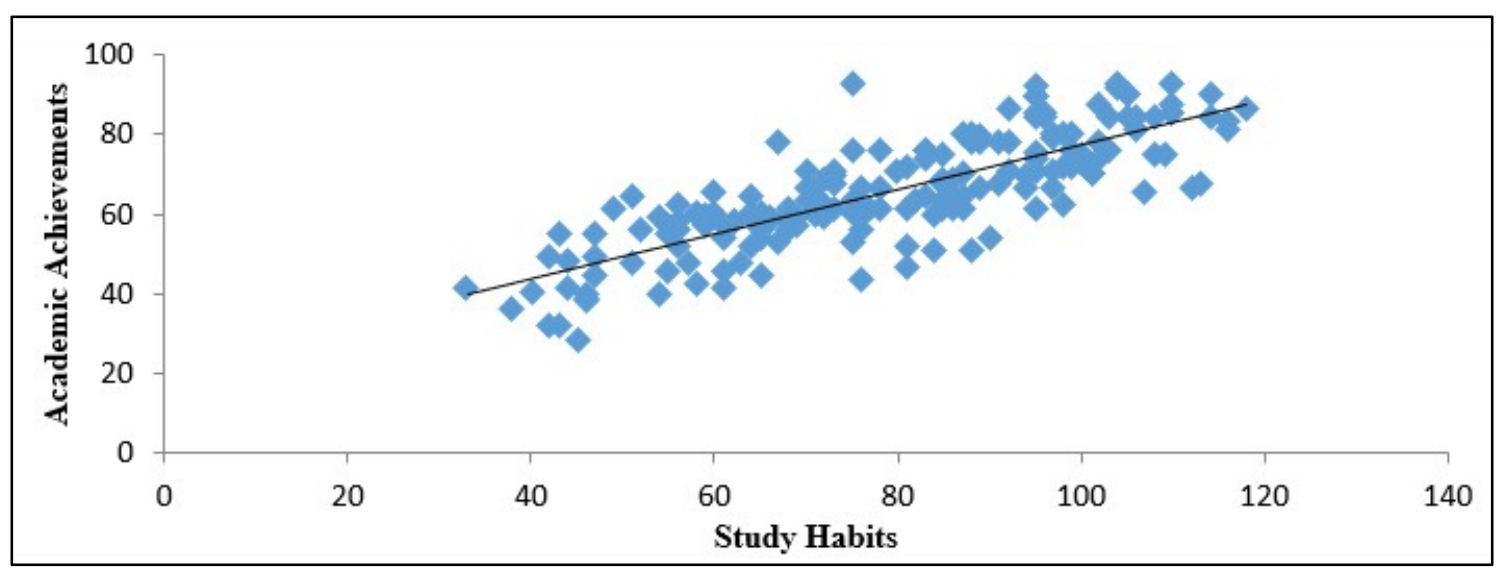

Figure 3. Scatter diagram showing positive correlation between Study Habits \& Academic Achievement of high school pupils. ( $\mathrm{n}=180$ )

\section{Discussion}

The present study focused on the relationship between the Study Habits \& Academic Achievements of high school pupils in a selected school at Alappuzha District and in this study the status of study habits showed that less than two thirds (61.7\%) of the subjects had satisfactory study habits, less than one third (29.5\%) had good study habits and less than one tenth (8.8\%) had bad study habits. A descriptive study was conducted at Pune city (2010) to determine the relationship between Study Habits \& Academic Achievements among 104 high school pupils of Spicer Higher Secondary School and the results revealed that $48.2 \%$ had average study habits, $25.9 \%$ had unsatisfactory study habits, $16.5 \%$ had good study habits and $9.4 \%$ had very unsatisfactory study habits. [11] In the present study, the selected high school pupils' academic achievement depicted that less than half (45.6\%) of subjects had good academic achievements, less than one third (31.7\%) had average academic achievements, less than one fifth (18.3\%) had excellent academic achievements, a few (4.4\%) had below average and none of them were in poor.

The correlation between the study habits and the academic achievements of high school pupils showed that the total mean score of study habits was 78.81 with SD 20.26 and the total mean score of academic achievements was 65.58 with SD 14.13. The calculated Karl Pearson correlation coefficient, ' $r$ ' value 0.808 which was greater than table value (0.191) with the degree of freedom 178 at $\mathrm{p}<0.0$ level of significance showed that there was a significant positive correlation between the study habits and the academic achievements of high school pupils. That means an increase in the score of study habits will also increase the academic achievements among high school pupils. A descriptive study was conducted at Karnataka (2014) to assess the influence of study habits on the academic performance among 250 higher primary school pupils (125 boys and 125 girls), and the results revealed that $60 \%$ of the boys, $63.20 \%$ of the girls had good study habits, $28.8 \%$ of the boys, $26.40 \%$ of the girls had average study habits and $11.20 \%$ of the boys, $10.40 \%$ of the girls had poor study habits and the relationship between boys and girls on study habits was found to be non-significant.[14]

Lastly, the researcher detected that there was a major relationship between study habits with age, gender, class of study, number of close friends, most favourite hobby, involvement in extra-curricular activities, failure in academic exams, habit of note taking and most frequently occurring health problems, and there was no significant association between religion, area of residence, type of family, family income per month, education of father, education of mother, occupation of father, occupation of mother, number of siblings, birth order, peer group interaction, total class attendance, most preferred time for study, parental pressure on academics, and habit of skipping breakfast. And also, the researcher found that there was a significant association between the pupils' academic achievement and their sociodemographic variables like gender, occupation of father, birth order, most favourite hobby, involvement in extra-curricular activities, failure in academic exams, and habit of note taking and no significant association between the age, religion, class of study, area of residence, type of family, family income per month, education of father, education of mother, occupation of mother, number of siblings, number of close friends, peer group interaction, total class attendance, most preferred time for study, parental pressure on academics, most frequently occurring health problems, and habit of skipping breakfast.

\section{Conclusions}

The outcome reveals that there was a positive correlation prevailing in between the study habits and the academic achievement of high school pupils. That means an increase in the score of study habits will also increase the academic achievement among high school pupils. So, 
the study settled that if pupils are maintaining satisfactory and proper study habits, then their academic achievement would definitely improve. Deprived study habits will upshot in a poor academic accomplishment. And also the study depicts that, sociodemographic variables like gender, most favorite hobby, involvement in extra-curricular activities, failure in academic exams, and habit of note taking influenced the study habits and the academic achievement of selected high school pupils.

\section{Recommendations}

Study habit is a significant correlate of academic achievement amongst pupils. The present study was conducted in school that is affiliated to CBSE. So for the future studies it is suggested to be carried out this similar study can be conducted in another settings like government schools in rural areas among more samples. Interventional studies can also be conducted to improve the level of academic achievement among high school pupils. Relative study can be steered to assess the study habits \& academic achievements among nursing and engineering college pupils.

\section{Acknowledgements}

I acknowledge my sincere gratitude to my guide Prof. (Mrs.) Anju A R, Vice principal, HOD (Child Health Nursing), Josco College of Nursing for her motivating direction, continuous encouragement, substantial guidance, ideas and support for the completion of the study.

\section{REFERENCES}

[1] Lamar R. "Study habits of higher secondary pupils of Shillong in Mathematics," IOSR Journal of Research \& Method in Education, Vol.4, No.2, 36-37.

[2] Darwin C, "Good study habits: secrets to school success,"www.slideshare.net/darwin1204/study-habits-for... (accessed Feb. 17, 2010)

[3] Premalakshmi K. "Study Habits \& Academic Achievement of higher secondary pupils," Scolarly Research Journal for Interdisciplinary Studies, Vol. 1, No.3, 554-555.

[4] Lawrence A S A. "Relationship between Study Habits \& Academic Achievement of higher secondary school pupils," Indian Journal of Applied Research, Vol.4, No.6, 143-145.

[5] Devi S S. "An investigation into the study habits of high school pupils in relation to their academic achievement in tribal area of Yercaud," Shanlax International Journal of Education, Vol.4, No.3, 13-15.

[6] Verma A. "A study of academic achievement among high school pupils in relation to their study habits," IMPACT: International Journal of Research in Humanities, Arts and Literature, Vol.4, No.3, 75-88.

[7] Illahi B Y, Khandai H. "Academic achievements and study habits of college pupils of district Pulwama," Journal of Education and Practice, Vol. 6, No.31, 1-3.

[8] Murthy C G V, Sherafat R. "A study of Study Habits \& Academic Achievement among secondary and senior secondary school pupils," The International Journal of Indian Psychology, Vol.3, No.2, 161-164.

[9] Chabra S, Bansal T, Misra M. "Does learning music affect study habits of learners," Scolarly Research Journal for Interdisciplinary Studies, Vol.1, No.2, 276-278.

[10] Shahidi F, Dowlatkhah H R, Avand A, Musavi S R and Mohammadi E. "A study on the quality of study skills of newly-admitted pupils of Fasa University of Medical Sciences," Journal of Advances in Medical Education \& Professionalism, Vol.2, No. 1, 45-50.

[11] Siahi E A, Maiyo J K. "Study of the relationship between Study Habits \& Academic Achievement of high school pupils: A case of spicer higher secondary school," International Journal of Educational Administration and Policy Studies, Vol.7, No.7, 134-138.

[12] Lale Cerrah Ozsevgec, Tugba Kontas Azakli. “An investigation on the Vocational High School Pupils' Learning Approaches in Terms of Various Variables," Universal Journal of Educational Research, Vol. 6, No.1, 184-189.

[13] Mutsotso N S, Abenga E S B. "Study methods for improving quality learning and performance in higher education," Educational Research and Reviews, Vol. 5, No.12, 808-813.

[14] Halayannavar R B, Gudaganavar N V. "Influence of study habits on academic performance of higher primary school pupils,” International Journal of Science and Research, Vol.3, No.2, 277-280. 